\title{
Guide and Instrument Upgrade at Helmholtz-Zentrum Berlin
}

Th. Krist, A. Tennant*

Helmholtz-Zentrum für Materialien und Energie, Hahn-Meitner-Platz 1, 14109 Berlin, Germany

In this article we present the results of the major upgrade program at Helmholtz-Zentrum Berlin (HZB) which has been successfully conducted from October 2010 to March 2012. We have earlier reported about the plans for this program in Neutron News 2009/2 [1].

The upgrade comprised the exchange of the cold source moderator cell and the complete guide system in the Neutron Guide Hall 1, which was rebuilt with an optimized geometry. Simultaneously several instruments were upgraded and most of them relocated to optimum positions. In Fig. 1 we show the new layout of the neutron scattering instrumentation at the HZB. It shows the experimental hall, the two neutron guide halls and the extension building to host the upgraded time-of-flight spectrometer NEAT V3.

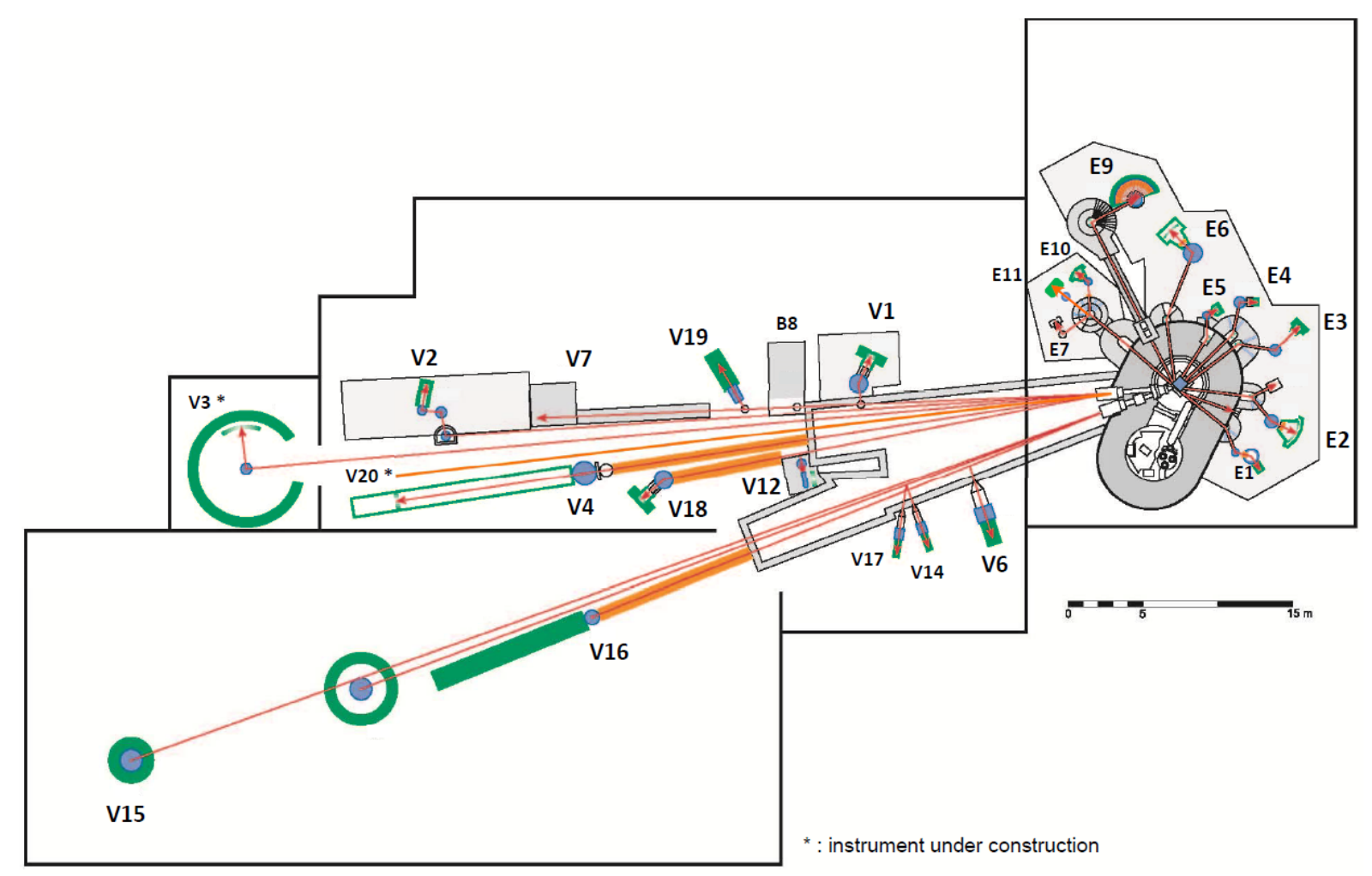

Fig. 1 Instruments in the reactor hall and the two neutron guide halls.

\section{Cold source and guide system}

The cold source moderator cell geometry was changed from a disc-like to a cup-like container volume which was a tremendous effort both technically as well as with respect to licensing. Similar changes at other sources were known to lead to a flux increase on the order of $50 \%$ [2, 3]. At BER II this factor gives rise to a true brilliance gain in the same order of magnitude. Precise measurements for all instruments are difficult since the whole guide system was exchanged at the same time.

Until 2010 the guide system in the first guide hall had five guides serving nine instruments. It consisted of an extraction system located in the reactor wall, a part in the main rotary shutter and finally the guides with all of their walls coated with ${ }^{58} \mathrm{Ni}$.

Extensive Monte Carlo simulations of all instruments have resulted in optimum parameters for the new guide system. Given the rather stringent time-constraint for production and installation for the more than $150 \mathrm{~m}$ of guide needed all three neutron guide producing companies, Mirrotron, S-DH and 
Swissneutronics as well as for some of the polarizing systems NOB where consigned to fabricate the neutron optical guide system.

The new guide system provides one more guide and comprises six guides in total. In order to maximize brilliance transfer most of the reflecting surfaces are coated with $m=3$ supermirrors. Details are given in Table 1. Increasing the angular range covered by the guides the additional guide NL2b could be set up. It hosts the so-called ESS-test beamline V20 which serves as a platform to test novel scattering techniques and instrument components, which are of immediate interest for the ESS. The neutron guides $1-3$ are now serving in Neutron Guide Hall 1 ten instruments with an eleventh one for polarized USANS being planned.

Table 1. The new guide system in Neutron Guide Hall 1

\begin{tabular}{|c|c|c|c|c|c|c|c|c|c|c|}
\hline \multirow{2}{*}{$\begin{array}{l}\text { Neutron } \\
\text { Guide }\end{array}$} & \multirow{2}{*}{$\begin{array}{l}\text { Instrument } \\
\text { installed }\end{array}$} & \multirow{2}{*}{$\begin{array}{c}\text { Guide } \\
\text { length } \\
{[\mathrm{m}]}\end{array}$} & \multirow{2}{*}{$\begin{array}{c}\begin{array}{c}\text { Inner } \\
\text { height } \\
{[\mathrm{mm}]}\end{array} \\
\end{array}$} & \multirow{2}{*}{$\begin{array}{l}\text { Inner } \\
\text { width } \\
\text { [mm] }\end{array}$} & \multirow{2}{*}{$\begin{array}{c}\text { Radius } \\
\text { of } \\
\text { curvature } \\
{[\mathrm{mm}]}\end{array}$} & \multicolumn{3}{|c|}{ Supermirror coating $\mathrm{m}$} & \multirow{2}{*}{$\begin{array}{l}\text { Gain } \\
\text { factor } \\
\text { expected }\end{array}$} & \multirow{2}{*}{$\begin{array}{l}\text { Gain } \\
\text { factor } \\
\text { realized }\end{array}$} \\
\hline & & & & & & $\begin{array}{l}\text { Inner } \\
\text { Wall }\end{array}$ & $\begin{array}{l}\text { Outer } \\
\text { Wall }\end{array}$ & $\begin{array}{l}\text { Up/ } \\
\text { Down }\end{array}$ & & \\
\hline $\begin{array}{l}\text { Extraction } \\
\text { part }\end{array}$ & $\begin{array}{l}\text { Common to all } \\
\text { guides }\end{array}$ & 3.4 & 125 & $\begin{array}{l}150- \\
332\end{array}$ & n.a. & 3 & 3 & 3 & n.a. & n.a. \\
\hline NG1a & V1 & 27 & 125 & 30 & 750 & 2.5 & 3 & 3 & 1.8 & 4 \\
\hline NG1a & $\begin{array}{l}\text { B8 Auto- } \\
\text { Radiography }\end{array}$ & 27 & 125 & 30 & 750 & 2.5 & 3 & 3 & 1.8 & 2 \\
\hline NG1a & V19 PONTO & 27 & 125 & 30 & 750 & 2.5 & 3 & 3 & 1.8 & n.a. \\
\hline NG1a & V7 CONRAD & 27 & 125 & 30 & 750 & 2.5 & 3 & 3 & 1.8 & $2.4-4$ \\
\hline NG1b & V2 FLEXX & 42 & 125 & 60 & 2800 & 3 & 3 & 3 & 5 & $8-11$ \\
\hline NG2a & V3 NEAT & 58 & 125 & 60 & 3000 & 1.5 & 3 & 1.5 & 5 & n.a. \\
\hline NG2b & V20 Test-BL & 41 & 125 & 60 & $\begin{array}{l}1500 \\
2300\end{array}$ & 3 & 3 & 3 & n.a. & n.a. \\
\hline NG3a & V4 SANS & 18 & 50 & 30 & 1300 & ${ }^{58} \mathrm{Ni}$ & ${ }^{58} \mathrm{Ni}$ & ${ }^{58} \mathrm{Ni}$ & 1 & 1 \\
\hline NG3b & V12 & 22 & 50 & 30 & 500 & 3 & 3 & 3 & 2.5 & n.a. \\
\hline NG3b & V18 BioRef & 22 & 50 & 30 & 500 & 3 & 3 & 3 & 2.5 & 2 \\
\hline
\end{tabular}

During the exchange of the guide system it was discovered that the first part of NL4 which mainly serves Neutron Guide Hall 2 showed severe degradation of the coating. This explained why already one year after the installation of the guide in 2005 the intensity of the neutrons with longer wavelengths had dropped to $60 \%$ and after four years to $40 \%$.

The substrates used on NL4 up to the end of the rotary shutter $4.95 \mathrm{~m}$ downstream from the cold source were made from float glass, followed by sections with Borofloat glass glass. All distances given in the following refer to the position relative to the cold source. The first section between $1.54 \mathrm{~m}$ and 8 $m$ is the first ever built bispectral beam extraction optics which is described in more detail in [1], where silicon wafers are placed in a wedge-shaped guide, with glass and silicon both coated with $m=3$ supermirrors.

A significant area of the extraction guide walls was damaged up to $8 \mathrm{~m}$. Here, the coating detached from the glass but stayed on the silicon wafers indicating a lower adhesion on glass and perhaps additionally a large stress. Neutron reflection curves from these wafers were only marginally below the values measured for unexposed wafers.

Consequently, during the recent upgrade float glass was chosen as substrate for the replacement guide up to $8 \mathrm{~m}$ counting on improvements in coating technology. 
This experience led us to set up a careful monitoring procedure: twice a year we check the neutron flux in all guides at $10 \mathrm{~m}$ and further downstream at some more positions by gold foil activation. Additionally all instruments have defined a standard configuration to determine the flux there once a month. The good news is that now, after one and a half years of reactor operation no loss in neutron flux was found and a fast degradation of the guides can be excluded. This indicates that the adhesion of the supermirror coating to the glass was improved and/or the stress was lowered.

For the guides NL1 to NL3 which were tendered a year before these findings we had been cautious enough to require float glass up to $10 \mathrm{~m}$, and then followed by Borofloat glass.

\section{Shielding}

The shielding for the old guides system featured a casemate of heavy concrete up to $10 \mathrm{~m}$ and of light concrete up to $25 \mathrm{~m}$, both with $80 \mathrm{~cm}$ thick walls, and further on a combination of polyethylene and lead around the guides. In the casemates there was no further shielding around the guides. The guides were made from Borkron glass and coated with ${ }^{58} \mathrm{Ni}$ and they all had a width of $3 \mathrm{~cm}$. Now, three of the new guides have a width of $6 \mathrm{~cm}$ and most of the guides have a coating of $\mathrm{Ni}-\mathrm{Ti}$ supermirrors with $m=3$. This leads to three important consequences:

Due to the doubled guide width for three guides the direct line of sight increased to $42 \mathrm{~m}$. Since the total guide cross section also doubled the amount of fast neutrons and gamma radiation entering the guide system from the reactor core doubled. Furthermore, due to the increased thickness of the guide coating from $0.1 \mu \mathrm{m}{ }^{58} \mathrm{Ni}$ to $3 \mu \mathrm{m} \mathrm{Ni}$ and Ti the gamma dose from nuclear reactions of the neutrons in the coating strongly increased.

To estimate the expected neutron and gamma radiation an extensive simulation of the reactor and the whole guide system was performed by Florian Grünauer [4]. The new shielding system was designed according to the results of his study. The main features are:

1. Guide substrates should be made from borated glass as close to the source as possible. Learning from the experience at the ILL and LLB about the limited lifetime of neutron guides made from borated glass and taking into account our reactor power of $10 \mathrm{MW}$ it was decided that from 1.54 $\mathrm{m}$ on float glass, from $4.95 \mathrm{~m}$ on Borkron glass and from $10 \mathrm{~m}$ on Borofloat glass should be used.

2. The shielding should start as close as possible to the guides.

We covered the guides with $3 \mathrm{~cm}$ thick plates made from PE with $5 \% \mathrm{~B}_{2} \mathrm{O}_{3}$ in a distance of a few $\mathrm{mm}$ to the guides starting at $4.95 \mathrm{~m}$. The next layer of shielding was put as close as possible.

3. The most efficient shielding was found to be a mixture of steel and the above mentioned borated PE with an averaged linear absorption coefficient of $0.18 \mathrm{~cm}^{-1}$ for the combined dose of gamma and neutron radiation, while heavy concrete has a value of $0.13 \mathrm{~cm}^{-1}$. For positions where a non-magnetic shielding was required the steel can be replaced by lead. Even though the homogeneous mixture of these materials turned out to be best a sandwich with layers of $1 \mathrm{~cm}$ thickness had nearly the same shielding efficiency.

In the region from $4.95 \mathrm{~m}$ to $25 \mathrm{~m}$ we applied a sandwich of $20 \mathrm{~cm}$ thickness around the guides extending down to the floor. The floor inside the shielding was covered by the borated PE with a thickness of $10 \mathrm{~cm}$. In this area the existing casemates with a wall thickness of $80 \mathrm{~cm}$ add to the shielding. The combined shielding efficiency at $10 \mathrm{~m}$ gives a factor of $10^{-6}$.

From $25 \mathrm{~m}$ on we built an entirely new casemate using a combination of heavy concrete with a density of $5.2 \mathrm{~g} / \mathrm{cm}^{3}$ and the PE/steel sandwich. The base blocks of the side walls up to $80 \mathrm{~cm}$ height and the roof were made from concrete. The pieces in between, from $80 \mathrm{~cm}$ to $200 \mathrm{~cm}$, close to the neutron guide at a height of $120 \mathrm{~cm}$, were made from containers filled with the sandwich materials in plates of $1 \mathrm{~cm}$ thickness. The total shielding thickness was for both materials $40 \mathrm{~cm}$.

In two areas around the samples of V2, FLEXX and V4, SANS the shielding was made from nonmagnetic heavy concrete with a density of $4.5 \mathrm{~g} / \mathrm{cm}^{3}$ and in the sandwich steel was replaced by lead. 
4. The radiation drops by an order of magnitude every $10 \mathrm{~m}$ and at the end of direct sight by nearly two orders of magnitude.

The end of sight was reached at $42 \mathrm{~m}$, therefore at $45 \mathrm{~m}$ the casemate was closed by an end wall made from borated PE and concrete. Further downstream the remaining guides NL1b, NL2a and $\mathrm{NL2} b$ have individual shieldings.

This shielding concept led to total radiation levels at the outer side of the shielding walls at positions away from experimental devices of below $2 \mu \mathrm{Sv} / \mathrm{h}$ with an error bar of $50 \%$.

Since these are similar levels as before the upgrade one can estimate the increase of radiation in the existing casemates. The additional $20 \mathrm{~cm}$ width of sandwich shielding there reduces the radiation by a factor of 36. Since the amount of fast neutrons and gamma radiation from the reactor core doubled the remaining factor of about 15 can be attributed to the change of the coating from $0.1 \mu \mathrm{m}{ }^{58} \mathrm{Ni}$ to $3 \mu \mathrm{m}$ $\mathrm{Ni}$-Ti supermirrors with $\mathrm{m}=3$. However, this factor should be used only as a rough estimate because it depends on the thickness of the shielding which has different absorption cross sections for different energy ranges.

We used simple carbon steel for the sandwich target to have a low Co content and now after one and a half years of reactor operation no activation of the steel can be measured against background levels of 0.5 to $1 \mu \mathrm{Sv} / \mathrm{h}$.

\section{Improvements at the instruments}

In the last column of table 1 the measured gain factors for all instruments in Neutron Guide Hall 1 are shown and below we give some short additional remarks. Some of the instruments are discussed in more detail in separate articles.

At the Membrane Diffractometer V1 gold foil activation measurements confirmed an increase in flux by a factor of 4 in front of the monochromator to $4 * 10^{9} \mathrm{~cm}^{-2} \mathrm{~s}^{-1}$. The neutron flux at the sample position also shows an increase in flux of a factor of 4 .

At the autoradiography station B8 the available intensity doubled.

For the polarized tomography PONTO, V19, the intensity cannot be compared to the old instrument because the instrument set up was changed.

The tomography station CONRAD V7 has an intensity gain of 10 at the end of the guide and of 2.4 at the sample. The gain due to the new set up amounts to a total gain of 4 .

At the triple-axis spectrometer FLEXX V2 intensity gains of $8-11$ were reached.

The inelastic time-of-flight spectrometer NEAT V3 is currently under construction and is expected to start the user operation in 2015.

The ESS test beamline V20 is at a new guide, thus not comparison is possible. The flux is $10^{9} \mathrm{ncm}^{-2} \mathrm{~s}^{-1}$ at the sample position. The instrument uses a double chopper to create a neutron pulse with the ESS time structure $(2.86 \mathrm{~ms}, 14 \mathrm{~Hz})$. A second double chopper serves as wavelength band filter. A cascade of four single disc choppers allows studying up to six-fold wavelength frame multiplication as a main concept to take full advantage of long neutron pulses in elastic scattering applications [5].

The beamline for the SANS V4 got a supermirror coating up $10 \mathrm{~m}$ but continued from there with the old ${ }^{58} \mathrm{Ni}$ guide up to $23 \mathrm{~m}$. At the sample an increase in flux of about 1.5 was measured, however with a large error bar of $30 \%$.

The diffractometer V12 is still being set up.

The time-of-flight reflectometer BioRef V18 has found a gain of 2 for the usually used set up with the very tight collimation of $0.005^{\circ}$.

At the guide NL4 in Neutron Guide Hall 1 the instruments V6, V14 and V17 and in Neutron Guide Hall 2 the instruments VSANS V16 and EXED V15 profited from the reconstruction of the bispectral beam extraction and found gains for the cold part of the spectrum in the order of 2.5 .

V16 is a TOF-SANS instrument aiming to reach very low momentum transfer down to $0.02 \mathrm{~nm}^{-1}$ in standard mode, which gives significantly better statistics in the low-q regime. Presently projects are underway for establishing RheoSANS, microfluids, in-situ light scattering, in-situ electrochemistry as well as gas adsorption measurements.

EXED (V15) is a novel time-of-flight (TOF) diffractometer optimized for conducting powder and single crystal experiments in angular restricted (extreme) sample environments. The High Field Magnet will 
be available on the instrument by the end of 2014 enabling unprecedented neutron scattering studies with magnetic fields beyond $25 \mathrm{~T}$. Currently EXED operates without angular restrictions and is available for users. The instrument can be run as a high resolution $\left(\Delta \mathrm{d} / \mathrm{d} \sim 10^{-3}\right.$ in backscattering) or high flux diffractometer. Four moveable detector banks combined with a broad wavelength range available from the bispectral source allow covering a large dynamic range from roughly one half to several tens of $\AA$. Typically, a high resolution powder diffraction pattern using the Fermi Chopper can be collected in a few hours. By relaxing the wavelength resolution, the flux can be increased by more than an order of magnitude.

\section{Conclusion}

The experimentally determined gain factors of $2-10$ meet and for some instruments exceed the expectations derived from Monte Carlo simulations. The new shielding performs excellently and as expected from the simulations and guarantees a safe environment. These results of the upgrade project conducted at BER II demonstrate real success and provide the basis for offering a successful user service.

\section{Acknowledgements}

I want to express my deeply felt thank to all technicians and instrument scientists working at the project and especially to Axel Rupp and Norbert Stüsser who all contributed to the project with great enthusiasm and engagement.

\section{References}

1. H. A. Graf, D. Clemens, O. Prokhnenko, H.-J- Bleif, C. Pappas, S. Welzel, Th. Krist, K. Habicht, M. Russina, Upgrade program for the Cold Neutron Instrumentation of the Helmholtz-Zentrum Berlin, Neutron News, 20.2, 16-19 (2009).

2. D. L. Selby et al., ORNL-Report, ORNL/TM-13498 (1998).

3. W. Knop, P. Schreiner, $7^{\text {th }}$ International UCN Workshop, $8-14$ Juni 2009 , Sankt Petersburg, Russland

4. F. Grünauer, Monte Carlo Simulationen zum Reaktorkern, der kalten Quelle und den vier Neutronenleitern am konischen Strahlrohr des Forschungsreaktors BER-II, 2010, not published.

5. M. Strobl, M. Bulat, K. Habicht, The wavelength frame multiplication chopper system for the ESS test beamline at the BER II reactor-A concept study of a fundamental ESS instrument principle, Nucl. Inst. and Meth. A 705 74-84 (2013).

Footnote for page 1: * A. Tennant now works at Oak Ridge National Laboratory 